\title{
META-ANALYSIS : EFFECT OF HEART FAILURE ON MORTALITY IN PATIENT WITH COVID-19
}

\author{
Hesthi Krisnawati
}

Masters Program in Public Health, Universitas Sebelas Maret

\begin{abstract}
Background: Coronavirus disease-2019 (COVID-19) is responsible for substantial morbidity and mortality worldwide. Cardiovascular disease is a common comorbidity in COVID-19 patients and has been associated with poor outcomes. A systematic review and meta-analysis was attempted to investigate the effect of heart failure on mortality in patients with COVID-19.

Subjects and Method: A systematic review and meta analysis study was conducted by collecting articles from Science Direct, Google Schoolar, and PubMed databases. Keywords used heart failure, mortality COVID-19, and COVID-19. The intervention was aromatherapy. It was compared with non-aromatherapy group. The study outcome was pain during stage-1 birth delivery. The inclusion criteria were full text, cohort study, published from 2019 to 2021, and reported adjusted Hazard ratio. Selected articles were assessed using random effect model run on RevMan 5.3.

Results: A meta-analysis involved 11 studies showed that heart failure increased the risk of mortality in COVID-19 patients $(\mathrm{aHR}=1.52 ; 95 \% \mathrm{CI}=1.27$ to $1.82 ; \mathrm{p}<0.001)$.

Conclusion: Heart failure increases the risk of mortality in COVID-19 patients.
\end{abstract}

Keywords: heart failure, COVID-19, mortality

\section{Correspondence:}

Hesthi Krisnawati. Masters Program in Public Health, Universitas Sebelas Maret. Jl. Ir. Sutami 36A, Surakarta 57126, Central Java. Email: hesthikrisna86@gmail.com. 